\title{
ANTHROPOMETRIC CHARACTERISTICS AND AEROBIC PERFORMANCE OF PROFESSIONAL SOCCER PLAYERS BY PLAYING POSITION AND AGE
}

original paper

() Wroclaw University of Health and Sport Sciences

DOI: https://doi.org/10.5114/hm.2022.110124

\author{
KOULLA PARPA ${ }^{1 \oplus}$, MARCOS MICHAELIDES ${ }^{2 \oplus}$ \\ ${ }^{1}$ University of Central Lancashire, Preston, United Kingdom \\ ${ }^{2}$ University of Central Lancashire, Pyla, Cyprus
}

\section{ABSTRACT}

Purpose. This study examined the impact of playing position and age on professional soccer players' anthropometric characteristics and aerobic performance.

Methods. A total of 308 professional soccer players $(25.42 \pm 4.66$ years, $178.88 \pm 6.13 \mathrm{~cm}, 76.72 \pm 7.05 \mathrm{~kg})$ from the Eastern Mediterranean participated in the study. They were divided into 5 playing positions (defenders, midfielders, full-backs, forwards, wingers) and categorized into 3 age groups (18-24, 25-29, 30-35 years). Anthropometric variables were recorded. In addition, maximal cardiopulmonary exercise testing on a treadmill was performed to assess the players' aerobic physical fitness.

Results. A two-way MANOVA factorial analysis indicated that there was a significant main effect of playing position $[F(12,25)=9.34, p<0.001]$ and age $[F(6,548)=6.80, p<0.001]$ on the anthropometric characteristics of the players. Moreover, the multivariate analysis implied a significant main effect of age $[F(4,448)=4.47, p=0.002]$ and a marginal significant effect of playing position $[F(8,448)=1.77, p=0.81]$ on maximal oxygen consumption and run times. However, there was no significant interaction between playing position and age.

Conclusions. The findings of the present study significantly contribute to understanding male soccer players' age-related and performance characteristics in the Eastern Mediterranean region. Our results can be applied to ensure training specificity, aid in contract arrangements and player replacement, and identify the best players for particular playing positions.

Key words: $\mathrm{VO}_{2} \max$, performance, body composition

\section{Introduction}

It is generally recognized that soccer performance depends upon a myriad of factors that include but are not limited to anthropometric characteristics of the players [1], physical fitness [2], tactical and technical skills [3, 4], seasonal [5, 6] and environmental factors [7], as well as genetic determinants [8]. A comprehensive interpretation and evaluation of soccer performance can become challenging if the complex interrelationships between the aforementioned factors are considered. Numerous studies affirm that players should maintain high cardiovascular fitness to meet the requirements of such a physically demanding sport in which high-intensity actions are interspersed with lowintensity activities [7, 9].

Physical fitness and anthropometric measurements of soccer players have been studied extensively. The differences in anthropometric characteristics often documented among professional soccer players usually depend on their playing position and the requirements of the positional tasks [10-12]. Alongside playing position, physiological profiling in elite male players has highlighted the influence of age on a range of physical characteristics [1, 12, 13]. With regard to anthropometric measurements, Brazilian soccer players were found to have different anthropometric characteristics (smaller stature and body weight) and maximal oxygen consumption $\left(\mathrm{VO}_{2} \mathrm{max}\right)$ profiles than European soccer players, which may be partially explained by the fact that the former group focuses more on the technical component than on the physical elements of the game [11]. In addition, Spanish and Italian leagues appear to have shorter and lighter players compared with English and German leagues [14].

Correspondence address: Koulla Parpa, University of Central Lancashire, University Avenue 12-14 Pyla, 7080, Cyprus, e-mail: kparpa@uclan.ac.uk, https://orcid.org/0000-0002-1139-7731

Received: May 22, 2021

Accepted for publication: October 17, 2021

Citation: Parpa K, Michaelides M. Anthropometric characteristics and aerobic performance of professional soccer players by playing position and age. Hum Mov. 2022;23(4):44-53; doi: https://doi.org/10.5114/hm.2022.110124. 
Regarding the playing position, midfielders generally spend less time standing and walking than the rest of the players [5]. Furthermore, midfielders cover more distance than full-backs, forwards, and defenders [5, 10]. Relevant research demonstrated that different playing positions had different physical demands when English Football Association Premier League soccer players were examined. The study indicated that players' position significantly influenced time spent sprinting, running, shuffling, skipping, and standing still [15], with defenders performing the highest amount of jogging, skipping, and shuffling movements and significantly less sprinting and running compared with the remaining positions. Furthermore, midfielders spent significantly less time standing still and shuffling and the most time running and sprinting [15].

In agreement were the results obtained by Di Salvo et al. [10] among Latin players. They indicated that sprinting characteristics were influenced by position, with wide midfielders completing more high-intensity activities during training sessions than any other position in order to achieve the performance level required during the match. Similarly, it has been verified that high-intensity running with and without ball possession is reduced during various phases of the game, and the activity profiles and fatigue patterns vary among the different playing positions [16]. Positional demands were also associated with age. A recent investigation demonstrated that despite the decreased high-intensity running performance of older wide midfielders and attackers ( 30 years and over), their overall physical efforts remained similar to those of younger players [17]. More specifically, the study revealed that professional soccer players aged over 30 years exhibited a significantly lower performance in the total distance covered, the number of fast runs, and the number of sprints compared with younger players (aged $\leq 30$ years). Despite those negative changes, the player's ability to make successful passes increased with age. These effects were confirmed for all positions except wide midfielders. The playing position is also partly dependent on age, as research indicates that goalkeepers are significantly older than midfielders and forwards, while defenders are older than forwards [14].

Finally, a recent study that investigated the influence of genetic variants on performance in speed, power, and strength of elite soccer players depending on their playing position showed that genetic variants such as the ACTN3 R allele, NOS3 Glu/Glu genotypes, and IL1RN*2 allele predisposed players to occupy the attacker or defender playing position in elite soccer, with those po- sitions exhibiting higher strength and power measures than midfielders [8]. Concurrently, midfielders had lower strength and power than other playing positions without relation to strength and power genes [8].

Regarding $\mathrm{VO}_{2}$ max, even though it is not the only determinant of success in soccer, an average of $60 \mathrm{ml} / \mathrm{kg} / \mathrm{min}$ has been suggested as a threshold for a satisfactory physiological attribute in men's elite football [18]. In addition to $\mathrm{VO}_{2} \max$, body fat percentage $(\mathrm{BF} \%)$ has been reported as an essential parameter for soccer players, as higher values can be associated with increased body weight. It was demonstrated that the $\mathrm{BF} \%$ of players participating in different divisions in Cyprus ranged 10-12\%, with no significant differences across playing standards or positions [19].

Conclusively, analysing the positional differences in performance characteristics, coupled with an in-depth understanding of the age-related differences, not only will add to the limited research that exists in the Eastern Mediterranean region but also can be applied to ensure training specificity, aid in contract arrangements and player replacement, and identify the best players for particular playing positions. Therefore, it is pertinent to investigate the effect of each factor separately and the impact of age-position interaction on anthropometric and performance characteristics. Therefore, this investigation aimed to assess the effect of playing position and age interaction on professional soccer players' anthropometric characteristics and aerobic performance by utilizing a series of anthropometric and performance measures.

\section{Material and methods}

\section{Participants}

A total of 308 professional soccer players participating in the first division in the Eastern Mediterranean volunteered to participate in this observational study. The data were collected over 2 consecutive preseason preparation periods from 5 different soccer clubs. The players were divided into 5 playing positions and categorized into 3 age groups. The 3 age groups were: 18-24 years, 25-29 years, and 30-35 years, while the 5 playing positions were: defenders, midfielders, full-backs, forwards, and wingers. Age, stature, body weight, and $\mathrm{BF} \%$ were recorded before testing. The aerobic physical fitness was assessed through incremental cardiopulmonary exercise testing (CPET) to exhaustion on a treadmill. It should be noted that all participants were familiar with the testing procedures 
as the process is part of their annual schedule. Participation in the study was voluntary, and all players were informed of the risks of the investigation. Athletes who reported musculoskeletal injuries within 6 months before the testing were excluded from the study. Furthermore, goalkeepers were not included in the statistical analysis. All athletes were advised to abstain from heavy physical activity on the day prior to testing. The measurements were obtained between 9:00 and 15:00.

\section{Procedure}

Anthropometric measurements were recorded by using a wall stadiometer (Leicester; Tanita, Tokyo, Japan) to determine the players' stature and a leg-to-leg bioelectrical impedance analyser (BC418MA; Tanita) to assess body composition. All participants were instructed to follow the standard bioelectrical impedance analysis guidelines [20] before the measurements were obtained. They proceeded with an incremental maximal CPET until they reached exhaustion on a treadmill ( $\mathrm{h} / \mathrm{p} /$ Cosmos Quasar med; $\mathrm{h} / \mathrm{p} /$ Cosmos Sports \& Medical GmbH, Nussdorf, Germany). A breath-bybreath analysis was performed on the Cosmed Quark CPET (Rome, Italy) system. Laboratory conditions were kept constant, with the temperature of $22 \pm 1^{\circ} \mathrm{C}$ and relative humidity of $50 \%$. The players were tested by following the modified Heck incremental maximal protocol, which had been previously validated for its reliability to test soccer players [21]. The test came to an end when the participant reached volitional fatigue or when there was no variation among the $\mathrm{VO}_{2}$ levels while the workload increased. $\mathrm{VO}_{2}$ max was detected after having the results filtered to identify the highest value for an average of 10 seconds.

\section{Statistical analysis}

SPSS 26.0 for Windows (SPSS Inc., Chicago, USA) was used to analyse the results. Means and standard deviations were calculated for all the parameters. The homogeneity of variance was verified with the BrownForsythe test. The assumptions of multicollinearity, equality of covariance, and normality were met for all the variables. A two-way MANOVA factorial analysis was utilized to examine the impact of playing position and age on various anthropometric and performance variables. Then, univariate ANOVA followed by posthoc tests served to determine the playing positions and age groups with a significant difference in stature, $\mathrm{BF} \%$, body weight, and performance variables $\left(\mathrm{VO}_{2} \mathrm{max}\right.$ and run time). Measures of effect size were reported with (partial) eta squared $\left(\eta^{2}\right)$ (0.01 indicated a small effect, 0.06 indicated a medium effect, and 0.14 indicated a large effect). The statistical significance of the results was accepted at $p<0.05$.

\section{Ethical approval}

The research related to human use has complied with all the relevant national regulations and institutional policies, has followed the tenets of the Declaration of Helsinki, and has been approved by the University of Central Lancashire Science, Technology, Engineering, Medicine and Health ethics committee board and the Cyprus National Committee on Bioethics.

\section{Informed consent}

Informed consent has been obtained from all individuals included in this study.

\section{Results}

The descriptive characteristics of the professional soccer players per playing position and age category are presented in Table 1 . The statistical analysis revealed a significant main effect of playing position $[F(12,725)=9.34, p<0.001$; Wilk's $\Lambda=0.684$, partial $\left.\eta^{2}=0.12\right]$ and age $[F(6,548)=6.80, p<0.001$; Wilk's $\Lambda=0.86$, partial $\left.\eta^{2}=0.07\right]$ on the anthropometric characteristics of the players. More specifically, the defenders and forwards were taller than the midfielders, full-backs, and wingers (Table 1). Furthermore, BF\% was demonstrated to be consistently higher in the older players of all playing positions (Table 1). In addition, the multivariate analysis indicated that there was a significant main effect of age $[F(4,448)=4.47, p=0.002$; Wilk's $\Lambda=0.940$, partial $\left.\eta^{2}=0.031\right]$ and a marginal significant effect of positional differences $[F(8,448)=$ $1.77, p=0.81$; Wilk's $\Lambda=0.940$, partial $\left.\eta^{2}=0.031\right]$ on $\mathrm{VO}_{2}$ max and run times. More specifically, younger midfielders, full-backs, and wingers had greater $\mathrm{VO}_{2} \max$ values than the forwards and defenders of any age group. Furthermore, the run time of midfielders was significantly greater than in the rest of the playing positions (Table 2).

However, there was no significant interaction between playing position and age. Univariate ANOVA analysis indicated significant differences in stature $\left[\left(F(4,267)=24.89, p<0.001\right.\right.$; partial $\left.\eta^{2}=0.27\right]$ (Figure 1) and body weight $[F(4,276)=18.76, p<0.001$; partial $\eta^{2}=0.21$ )] (Figure 2) but not in BF\% among 
Table 1. Descriptive characteristics of the professional soccer players per playing position and age category

\begin{tabular}{lccccc}
\hline Playing position & Age group & $\begin{array}{c}\text { Height }(\mathrm{cm}) \\
M \pm S D\end{array}$ & $\begin{array}{c}\text { Weight }(\mathrm{kg}) \\
M \pm S D\end{array}$ & $\begin{array}{c}\text { Body fat (\%) } \\
M \pm S D\end{array}$ & $n$ \\
\hline \multirow{4}{*}{ Defenders } & $18-24$ & $180.92 \pm 5.45$ & $76.64 \pm 6.03$ & $11.02 \pm 2.98$ & 31 \\
& $25-29$ & $183.52 \pm 6.38$ & $82.05 \pm 7.02$ & $11.55 \pm 3.56$ & 24 \\
& $30-35$ & $185.57 \pm 3.92$ & $82.89 \pm 5.65$ & $11.76 \pm 2.26$ & 14 \\
& Total & $182.77 \pm 5.76$ & $79.79 \pm 6.86$ & $11.35 \pm 3.05$ & 69 \\
\hline \multirow{3}{*}{ Midfielders } & $18-24$ & $176.50 \pm 5.08$ & $72.81 \pm 4.58$ & $10.58 \pm 2.67$ & 31 \\
& $25-29$ & $177.62 \pm 5.73$ & $76.34 \pm 5.39$ & $11.37 \pm 1.76$ & 29 \\
& $30-35$ & $177.91 \pm 6.00$ & $76.34 \pm 5.80$ & $12.11 \pm 2.26$ & 27 \\
Full-backs & Total & $177.31 \pm 5.57$ & $75.08 \pm 5.46$ & $11.32 \pm 2.33$ & 87 \\
& $18-24$ & $175.69 \pm 4.16$ & $71.62 \pm 5.24$ & $11.56 \pm 2.60$ & 18 \\
& $25-29$ & $177.39 \pm 5.23$ & $75.17 \pm 6.49$ & $10.41 \pm 2.60$ & 18 \\
Forwards & $30-35$ & $178.44 \pm 3.03$ & $76.52 \pm 4.04$ & $12.95 \pm 2.50$ & 17 \\
& Total & $177.15 \pm 4.33$ & $74.39 \pm 5.67$ & $11.61 \pm 2.73$ & 53 \\
\hline \multirow{3}{*}{ Wingers } & $18-24$ & $182.28 \pm 5.36$ & $80.14 \pm 7.16$ & $10.26 \pm 2.79$ & 18 \\
& $25-29$ & $183.61 \pm 8.57$ & $85.33 \pm 10.65$ & $13.86 \pm 4.19$ & 9 \\
& $30-35$ & $182.62 \pm 4.98$ & $81.85 \pm 4.82$ & $11.68 \pm 2.82$ & 13 \\
& Total & $182.69 \pm 5.96$ & $81.87 \pm 7.54$ & $11.53 \pm 3.39$ & 40 \\
\hline
\end{tabular}

Table 2. The differences among playing positions in run times and $\mathrm{VO}_{2} \max$

\begin{tabular}{lccccc}
\hline \multirow{2}{*}{ Dependent variable } & Position & Mean & \multirow{2}{*}{$\begin{array}{c}\text { Standard } \\
\text { error }\end{array}$} & \multicolumn{2}{c}{ 95\% confidence interval } \\
\cline { 5 - 6 } & & & & Lower bound & Upper bound \\
\hline \multirow{3}{*}{ Run time (min) } & Defender & 15.69 & 0.24 & 15.22 & 16.17 \\
& Midfielder & $16.74^{*}$ & 0.19 & 16.35 & 17.12 \\
& Full-back & 16.42 & 0.26 & 15.91 & 16.92 \\
& Forward & 16.10 & 0.30 & 15.52 & 16.68 \\
& Winger & 16.48 & 0.29 & 15.91 & 17.05 \\
\hline \multirow{2}{*}{$\mathrm{VO}_{2} \max (\mathrm{ml} / \mathrm{kg} / \mathrm{min})$} & Defender & 57.18 & 0.81 & 55.57 & 58.78 \\
& Midfielder & 58.83 & 0.66 & 57.53 & 60.12 \\
& Full-back & 57.47 & 0.88 & 55.75 & 59.20 \\
& Forward & 56.58 & 1.00 & 54.60 & 58.56 \\
& Winger & 58.91 & 0.98 & 56.98 & 60.84 \\
\hline
\end{tabular}

$\mathrm{VO}_{2} \mathrm{max}$ - maximal oxygen consumption

* $p<0.05$

the playing positions. For the independent variable of age group, the results demonstrated significant differences in stature $[F(2,276)=4.45, p<0.05$; partial $\left.\eta^{2}=0.031\right]$, body weight $[F(2,276)=17.00, p<0.001$; partial $\left.\eta^{2}=0.113\right]$, and $\mathrm{BF} \%[F(2,276)=9.13, p<0.001$; partial $\left.\eta^{2}=0.065\right]$. Furthermore, post-hoc multiple comparisons revealed that the age group of 30-35 years was significantly taller $(p<0.05)$ than the younger groups. In addition, the age group of 18-24 years had significantly lower body weight, $\mathrm{BF} \%$, and stature ( $p<$ $0.05)$ than the older groups. Also, post-hoc analysis by playing position indicated that the defenders and forwards were significantly taller and heavier $(p<0.05)$ than the rest of the positions. However, $\mathrm{BF} \%$ exhibited no significant difference among playing positions.

The differences in run times and $\mathrm{VO}_{2}$ max among the playing positions are presented in Table 2 . The only significant difference $[F(4,239)=3.29, p=0.018$; par- 


\section{HUMAN MOVEMENT}

K. Parpa, M. Michaelides, Characteristics of professional soccer players

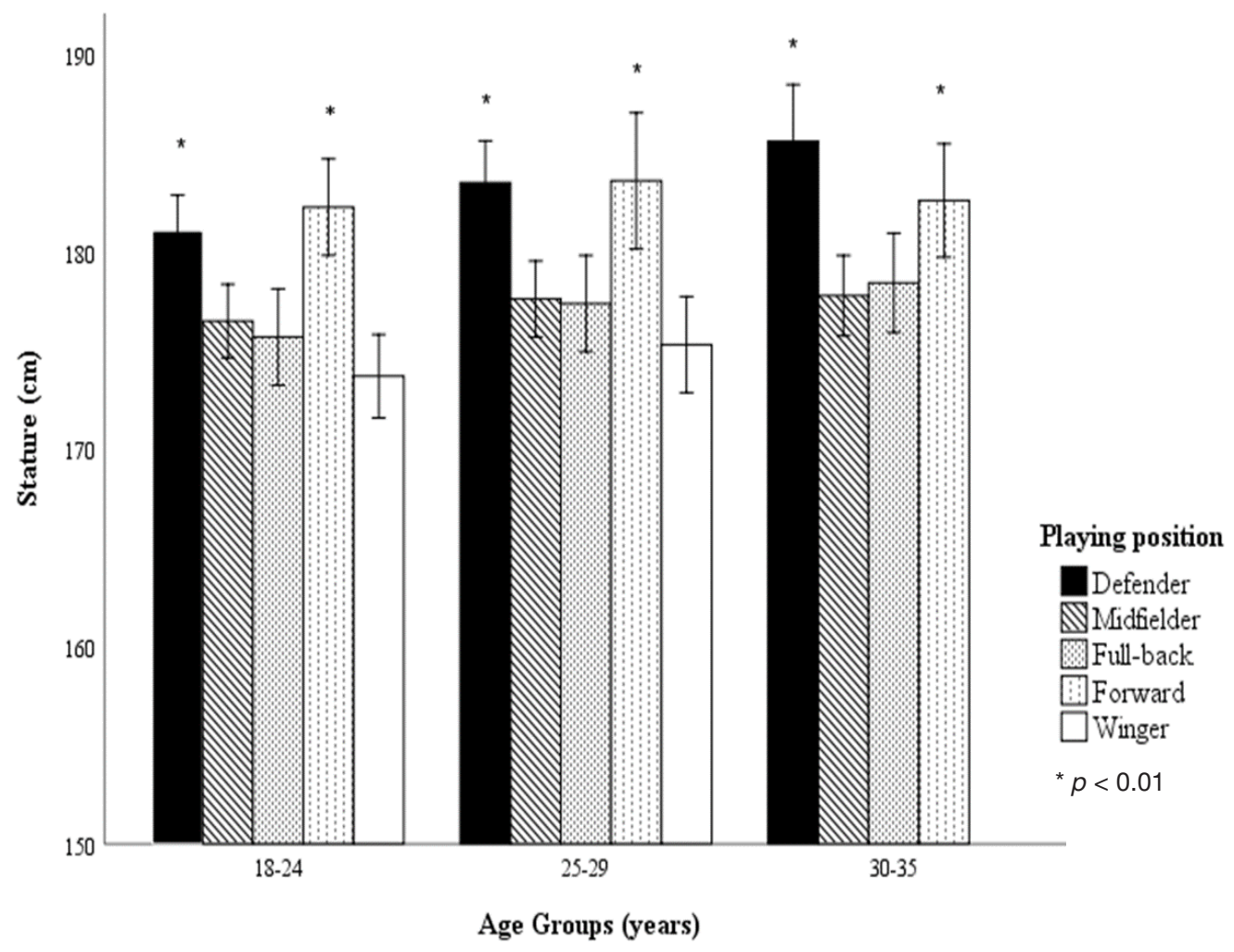

Figure 1. Stature of the players by age and position

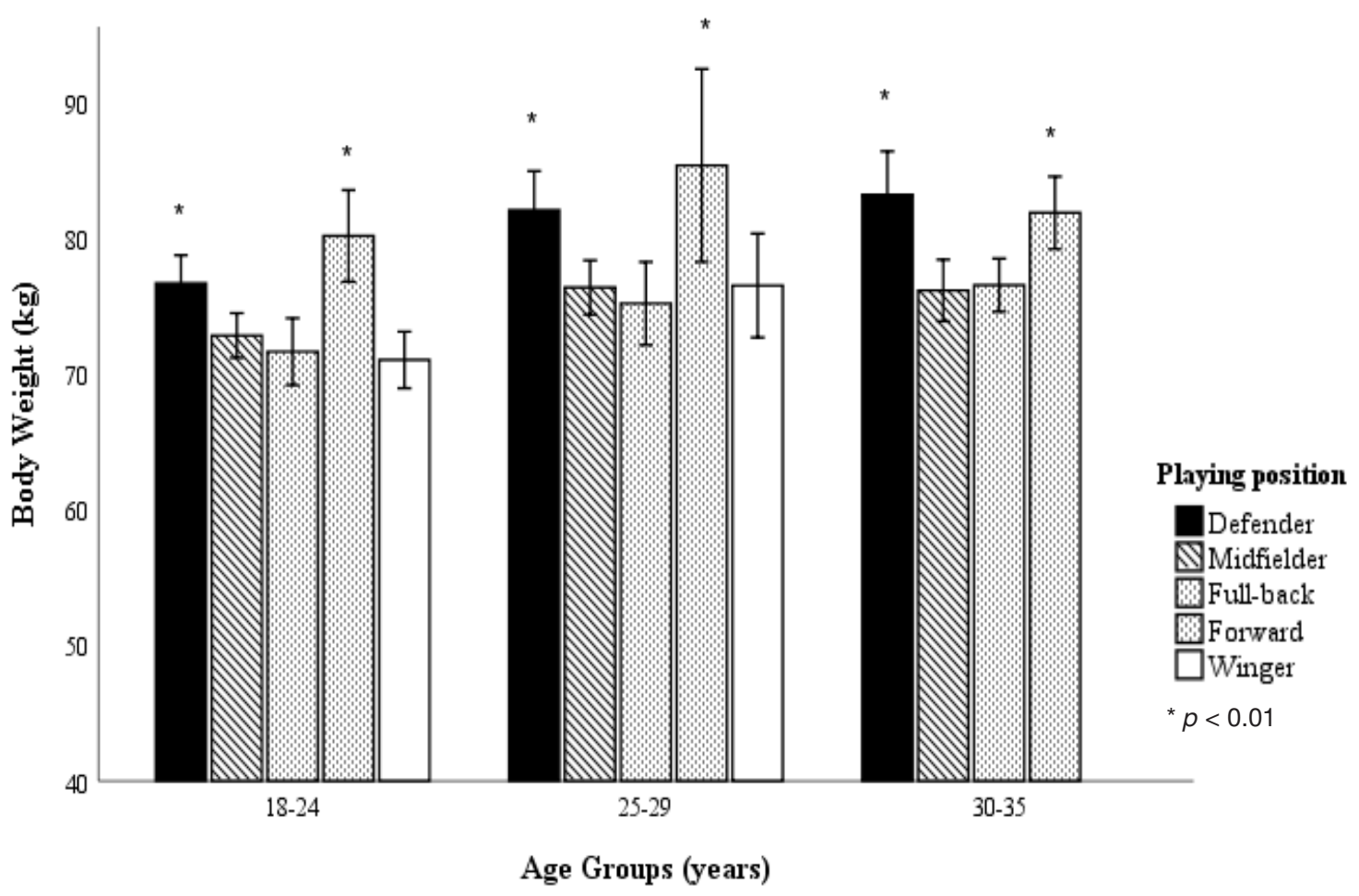

Figure 2. Body weight of the players by age and position 
Table 3a. Age differences for run time and $\mathrm{VO}_{2} \max$

\begin{tabular}{llcc}
\hline Age group & Parameter & Run time $(\mathrm{min})$ & VO2max $(\mathrm{ml} / \mathrm{kg} / \mathrm{min})$ \\
\hline \multirow{4}{*}{$18-24$} & Mean & 16.48 & $59.48^{*}$ \\
& Standard deviation & 1.67 & 6.06 \\
& $n$ & 107 & 118 \\
& Standard error of mean & 0.16 & 0.56 \\
\hline \multirow{3}{*}{$25-29$} & Mean & 16.43 & 57.24 \\
& Standard deviation & 1.63 & 5.38 \\
& $n$ & 87 & 92 \\
& Standard error of mean & 0.17 & 0.56 \\
\hline \multirow{3}{*}{$30-35$} & Mean & 16.15 & 56.34 \\
& Standard deviation & 1.77 & 5.26 \\
& $n$ & 58 & 63 \\
& Standard error of mean & 0.23 & 0.66 \\
\hline
\end{tabular}

$\mathrm{VO}_{2} \max$ - maximal oxygen consumption

${ }^{*} p<0.05$

Table $3 \mathrm{~b}$. Age position interaction differences for run time and $\mathrm{VO}_{2} \max$

\begin{tabular}{|c|c|c|c|c|c|c|}
\hline \multirow{2}{*}{ Dependent variable } & \multirow{2}{*}{ Position } & \multirow{2}{*}{ Age group } & \multirow{2}{*}{ Mean } & \multirow{2}{*}{$\begin{array}{c}\text { Standard } \\
\text { error }\end{array}$} & \multicolumn{2}{|c|}{$95 \%$ confidence interval } \\
\hline & & & & & Lower bound & Upper bound \\
\hline \multirow{15}{*}{ Run time (min) } & \multirow{3}{*}{ Defender } & $18-24$ & 15.61 & 0.31 & 15.00 & 16.22 \\
\hline & & $25-29$ & 16.20 & 0.35 & 15.52 & 16.89 \\
\hline & & $30-35$ & 15.27 & 0.55 & 14.19 & 16.34 \\
\hline & \multirow{3}{*}{ Midfielder } & $18-24$ & 16.58 & 0.33 & 15.93 & 17.23 \\
\hline & & $25-29$ & 16.82 & 0.33 & 16.17 & 17.46 \\
\hline & & $30-35$ & 16.81 & 0.35 & 16.12 & 17.50 \\
\hline & \multirow{3}{*}{ Full-back } & $18-24$ & 17.04 & 0.45 & 16.15 & 17.94 \\
\hline & & $25-29$ & 16.72 & 0.41 & 15.91 & 17.53 \\
\hline & & $30-35$ & 15.48 & 0.47 & 14.55 & 16.42 \\
\hline & \multirow{3}{*}{ Forward } & $18-24$ & 17.22 & 0.42 & 16.39 & 18.05 \\
\hline & & $25-29$ & 15.08 & 0.62 & 13.86 & 16.30 \\
\hline & & $30-35$ & 16.00 & 0.47 & 15.07 & 16.94 \\
\hline & \multirow{3}{*}{ Winger } & $18-24$ & 16.71 & 0.38 & 15.97 & 17.45 \\
\hline & & $25-29$ & 16.25 & 0.44 & 15.39 & 17.11 \\
\hline & & $30-35$ & & & & \\
\hline \multirow{15}{*}{$\mathrm{VO}_{2} \max (\mathrm{ml} / \mathrm{kg} / \mathrm{min})$} & \multirow{3}{*}{ Defender } & $18-24$ & 57.15 & 1.05 & 55.08 & 59.22 \\
\hline & & $25-29$ & 58.14 & 1.19 & 55.80 & 60.48 \\
\hline & & $30-35$ & 56.25 & 1.86 & 52.59 & 59.91 \\
\hline & \multirow{3}{*}{ Midfielder } & $18-24$ & 60.55 & 1.11 & 58.36 & 62.75 \\
\hline & & $25-29$ & 58.31 & 1.11 & 56.11 & 60.50 \\
\hline & & $30-35$ & 57.62 & 1.19 & 55.28 & 59.96 \\
\hline & \multirow{3}{*}{ Full-back } & $18-24$ & 60.09 & 1.54 & 57.05 & 63.13 \\
\hline & & $25-29$ & 57.91 & 1.39 & 55.17 & 60.65 \\
\hline & & $30-35$ & 54.43 & 1.61 & 51.26 & 57.59 \\
\hline & \multirow{3}{*}{ Forward } & $18-24$ & 59.22 & 1.44 & 56.39 & 62.06 \\
\hline & & $25-29$ & 54.66 & 2.10 & 50.51 & 58.81 \\
\hline & & $30-35$ & 55.85 & 1.61 & 52.68 & 59.02 \\
\hline & \multirow{3}{*}{ Winger } & $18-24$ & 62.20 & 1.28 & 59.68 & 64.71 \\
\hline & & $25-29$ & 55.62 & 1.49 & 52.69 & 58.55 \\
\hline & & $30-35$ & & & & \\
\hline
\end{tabular}


tial $\left.\eta^{2}=0.051\right]$ observed was in the run time between the midfielders and defenders, with the defenders running significantly shorter on the treadmill. Finally, the analysis demonstrated that the professional soccer players within the age group of 18-24 years had significantly greater $\mathrm{VO}_{2}$ max than the older groups (Table 3a) but with no playing position interaction (Table 3b).

\section{Discussion}

The current study aimed to assess the impact of age and playing position on the anthropometric characteristics and aerobic performance of professional male soccer players in the Eastern Mediterranean region. The study indicated a significant main effect of playing position and age on anthropometric variables and performance. However, there was no significant interaction between playing position and age. Younger players (18-24 years) demonstrated significantly lower body weight, $\mathrm{BF} \%$, and stature, while the older age group (30-35 years) was significantly taller. In addition, defenders and forwards were significantly taller and heavier than the rest of the playing positions, while their $\mathrm{BF} \%$ was not significantly different.

The positional differences observed in this study are in agreement with previous findings presented on English Premier League players where defenders were taller than midfielders but not significantly taller than forwards [22]. Similarly, it was demonstrated that defenders were taller and heavier than the remaining playing positions except for goalkeepers [23]. The differences in stature between the defenders and forwards compared with the rest of the playing positions reflect the demands of those positions, with increased stature being an essential component of their success. Evidence suggested that anthropometric characteristics may impact on soccer success, with stature and body weight being advantageous for certain positions, such as goalkeepers, defenders, and attackers [24]. This study indicated that defenders and forwards were significantly taller and heavier than the rest of the playing positions, while their $\mathrm{BF} \%$ was not significantly different, which implies that the increased body mass may be attributed to increased stature or increased muscle mass. These results may also be explained by a study demonstrating that certain genetic variants predisposed players to occupy the attacker or defender playing position in elite soccer, with those positions exhibiting higher strength and power measures and thus increased muscle mass than midfielders [8]. On the contrary, a review indicated positional differences in $\mathrm{BF} \%$ : midfielders presented the lowest $\mathrm{BF} \%$, while others reported that only the goalkeepers' and defenders' $\mathrm{BF} \%$ was greater than that of midfielders [25]. An additional study revealed significant in-season variations in BF\% (between start- and mid-season and midand end-season) and fat-free body mass (between startand mid-season and start- and end-season), while the body mass remained unchanged [26]. The same investigation confirmed that the fluctuations in $\mathrm{BF} \%$ and fat-free body mass at different points of the season differed across the positional groups, especially in defenders and midfielders, while no association was observed between measures and exposure time [26].

The positional requirements explain why midfielders must be explosive, lighter, and shorter [5]. Most differences between positions are related to defenders' completing less actions and distances than other outfield playing positions [27]. Furthermore, defenders operate in a relatively small area in the field. They thus have reduced opportunities to produce high-speed efforts and have fewer accelerations and decelerations relative to other playing positions [11], which may explain why they are taller and heavier than the rest of the playing positions, especially midfielders.

Even though the aging process has an impact on physical fitness [1], it is debatable whether the performance of elite soccer players during the games is indeed compromised. Research indicates that it is common for goalkeepers to be older than midfielders and forwards, while defenders appear to be older than forwards [14]. A recent study investigating the effect of age on different positional demands demonstrated that although high-intensity running performance decreased with advancing age, older wide midfielders and attackers (30 years and over) who were still playing in the league presented similar physical efforts [17]. Our study revealed that the only significant difference in the run times was between the midfielders and defenders, with the defenders demonstrating shorter running time, while age did not affect the running time on the treadmill. Interestingly, out of the 308 professional soccer players involved in this investigation, none of the participants over the age of 30 was reported in the winger playing position group. An additional study demonstrated that an aging trend had occurred in the previous 3 decades, with the players' average age rising from 24.9 to 26.5 years [28]. Furthermore, the researchers indicated that goalkeepers and centre backs tended to peak later than attackers, and their peak performance could last until the age of about 31 years [28]. 
With regard to $\mathrm{VO}_{2}$ max, this study showed that the age group of 18-24 years had significantly greater $\mathrm{VO}_{2}$ max values than the older groups but with no playing position interaction, implying that the differences existed despite the playing position of the players. Botek et al. [1] observed that older players ( $>30$ years) presented significantly lower $\mathrm{VO}_{2}$ max values, stating that it did not necessarily mean a decline in performance as it might be explained by the decrease of maximal heart rate in the oldest players. While some studies reported that midfielders had higher $\mathrm{VO}_{2} \max$ values than the rest [29], other investigators indicated no significant differences in $\mathrm{VO}_{2}$ max values among the different playing positions. At the same time, they suggested that $\mathrm{VO}_{2}$ max was not a good discriminator of aerobic fitness [30]. Specifically, Modric et al. [30] confirmed that the running speeds at the aerobic and anaerobic thresholds were better indicators of aerobic fitness in soccer players at different playing positions. In our study, aerobic performance, as determined by the running time on the treadmill, was only influenced by the playing position and not by age.

When considering positional differences and age, it needs to be highlighted that the role of the midfield player is to support both attacking and defensive activities, whereas defenders are predominantly involved in defensive activities. Furthermore, players' technical abilities, decision-making, game intelligence, and team tactics are essential factors that might influence the execution of technical tasks [31]. All the points mentioned above may explain the results of an investigation which demonstrated that defenders were older and more experienced than both the midfielders and attackers. Conclusively, the lower physical demand for defenders is likely why they tend to peak at a later age and maintain high performance at an older age [28].

\section{Conclusions}

The present findings significantly contribute to understanding male soccer players' age-related and performance characteristics. The results of this study may provide valuable information for coaches and managers to guide decisions regarding training strategies, player selection based on the anthropometric and physical demands of each position, and contract policies, e.g. with reference to when a new contract would be signed or when to replace or transfer a player on the basis of their age and playing position. Special consideration should be given to players over 30 years, especially if they are defenders. Also, a more extensive evaluation should be conducted for forwards, midfielders, and wingers, given the higher physical demands of those positions. It is interesting to note that among the 308 players involved in the study, no wingers over the age of 30 were identified. Furthermore, in the context of our results, it is pertinent that coaches and practitioners create position-specific conditioning programs with different training loads to reflect the demands of each playing position. Also, understanding the positional differences in performance characteristics, coupled with an in-depth knowledge of the age-related differences, may allow coaches to make specific adjustments when certain game strategies are to be employed. For example, more mature defensive players who have more technical skills may be selected if the game requires adopting more defensive tactics.

To our knowledge, this is one of the few studies that included only professional adult male players of the first division in the region to examine the impact of age and playing position on anthropometric characteristics and physical fitness. Future longitudinal studies utilizing the global positioning system and video analysis are required to provide conclusive evidence on the effects of age on competitive game performance. It should be noted that the current data only provide a snapshot of the physical characteristics of players and, consequently, fail to establish any within- or betweenseason changes in anthropometric characteristics or performance.

\section{Disclosure statement}

No author has any financial interest or received any financial benefit from this research.

\section{Conflict of interest}

The authors state no conflict of interest.

\section{References}

1. Botek M, Krejčí J, McKune AJ, Klimešová I. Somatic, endurance performance and heart rate variability profiles of professional soccer players grouped according to age. J Hum Kinet. 2016;54(1):65-74; doi: 10.1515/ hukin-2016-0035.

2. Strøyer J, Hansen L, Klausen K. Physiological profile and activity pattern of young soccer players during match play. Med Sci Sports Exerc. 2004;36(1):168-174; doi: 10.1249/01.MSS.0000106187.05259.96.

3. Gregson W, Drust B, Atkinson G, Salvo VD. Match-tomatch variability of high-speed activities in Premier League soccer. Int J Sports Med. 2010;31(4):237-242; doi: 10.1055/s-0030-1247546.

4. Castellano J, Blanco-Villaseñor A, Alvarez D. Contextual variables and time-motion analysis in soccer. Int J Sports Med. 2011;32(6):415-421; doi: 10.1055/s-00 31-1271771. 
K. Parpa, M. Michaelides, Characteristics of professional soccer players

5. Rampinini E, Coutts AJ, Castagna C, Sassi R, Impellizzeri FM. Variation in top level soccer match performance. Int J Sports Med. 2007;28(12):1018-1024; doi: 10.1055/s-2007-965158.

6. Parpa K, Michaelides MA. The effect of transition period on performance parameters in elite female soccer players. Int J Sports Med. 2020;41(8):528-532; doi: 10.1055/a-1103-2038.

7. Carling C, Dupont G, Le Gall F. The effect of a cold environment on physical activity profiles in elite soccer match-play. Int J Sports Med. 2011;32(7):542-545; doi: 10.1055/s-0031-1273711.

8. Petr M, Thiel D, Kvapilová K, Brož P, Malý T, Zahálka F, et al. Speed and power-related gene polymorphisms associated with playing position in elite soccer players. Biol Sport. 2022;39(2):355-366; doi: 10.5114/biolsport.2022.105333.

9. Reilly T. Energetics of high-intensity exercise (soccer) with particular reference to fatigue. J Sports Sci. 1997; 15(3):257-263; doi: 10.1080/026404197367263.

10. Di Salvo V, Baron R, González-Haro C, Gormasz C, Pigozzi F, Bachl N. Sprinting analysis of elite soccer players during European Champions League and UEFA Cup matches. J Sports Sci. 2010;28(14):1489-1494; doi: 10.1080/02640414.2010.521166.

11. Da Silva CD, Bloomfield J, Marins JC. A review of stature, body mass and maximal oxygen uptake profiles of U17, U20 and first division players in Brazilian soccer. J Sports Sci Med. 2008;7(3):309-319.

12. Scoz RD, Oliveira Alves BM, Lima Burigo R, Vieira ER, Alves Ferreira LM, da Silva RA, et al. Strength development according with age and position: a 10-year study of 570 soccer players. BMJ Open Sport Exerc Med. 2021;7(1):e000927; doi: 10.1136/bmjsem-2020-000927.

13. Hulse MA, Morris JG, Hawkins RD, Hodson A, Nevill AM, Nevill ME. A field-test battery for elite, young soccer players. Int J Sports Med. 2013;34(4):302-311; doi: 10.1055/s-0032-1312603.

14. Bloomfield J, Polman R, Butterly R, O’Donoghue P. Analysis of age, stature, body mass, BMI and quality of elite soccer players from 4 European leagues. J Sports Med Phys Fitness. 2005;45(1):58-67.

15. Bloomfield J, Polman R, O’Donoghue P. Physical demands of different positions in FA Premier League soccer. J Sports Sci Med. 2007;6(1):63-70.

16. Bradley PS, Sheldon W, Wooster B, Olsen P, Boanas P, Krustrup P. High-intensity running in English FA Premier League soccer matches. J Sports Sci. 2009;27(2): 159-168; doi: 10.1080/02640410802512775.

17. Sal de Rellán-Guerra A, Rey E, Kalén A, Lago-Peñas C. Age-related physical and technical match performance changes in elite soccer players. Scand J Med Sci Sports. 2019;29(9):1421-1427; doi: 10.1111/sms.13463.

18. Reilly T. Motion analysis and physiological demands. In: Reilly T (ed.), Science and soccer. London: E \& FN Spon; 1996; 65-81.
19. Marcos MA, Koulla PM, Anthos ZI. Preseason maximal aerobic power in professional soccer players among different divisions. J Strength Cond Res. 2018;32(2):356363; doi: 10.1519/JSC.0000000000001810.

20. Kyle UG, Bosaeus I, De Lorenzo AD, Deurenberg P, Elia M, Gómez JM, et al. Bioelectrical impedance analysis - part I: review of principles and methods. Clin Nutr. 2004;23(5):1226-1243; doi: 10.1016/j.clnu.2004.06.004.

21. Santos-Silva PR, Fonseca AJ, de Castro AW, D’Andréa Greve JM, Hernandez AJ. Reproducibility of maximum aerobic power $\left(\mathrm{VO}_{2} \max \right)$ among soccer players using a modified Heck protocol. Clinics. 2007;62(4):391396; doi: 10.1590/s1807-59322007000400004.

22. Sutton L, Scott M, Wallace J, Reilly T. Body composition of English Premier League soccer players: influence of playing position, international status, and ethnicity. J Sports Sci. 2009;27(10):1019-1026; doi: 10.1080/026 40410903030305.

23. Gil SM, Gil J, Ruiz F, Irazusta A, Irazusta J. Physiological and anthropometric characteristics of young soccer players according to their playing position: relevance for the selection process. J Strength Cond Res. 2007;21(2):438-445; doi: 10.1519/R-19995.1.

24. Joksimović M, Skrypchenko I, Yarymbash K, Fulurija D, Nasrolahi S, Pantović M. Anthropometric characteristics of professional football players in relation to the playing position and their significance for success in the game. Pedagog Psychol Med Biol Probl Phys Train Sports. 2019;23(5):224-230; doi: 10.15561/18189172. 2019.0503.

25. Slimani M, Znazen H, Miarka B, Bragazzi NL. Maximum oxygen uptake of male soccer players according to their competitive level, playing position and age group: implication from a network meta-analysis. J Hum Kinet. 2019;66(1):233-245; doi: 10.2478/hukin-2018-0060.

26. Carling C, Orhant E. Variation in body composition in professional soccer players: interseasonal and intraseasonal changes and the effects of exposure time and player position. J Strength Cond Res. 2010;24(5):13321339; doi: 10.1519/JSC.0b013e3181cc6154.

27. Molinos Domene Á. Evaluation of movement and physiological demands of full-back and center-back soccer players using global positioning systems. J Hum Sport Exerc. 2013;8(4):1015-1028; doi: 10.4100/jhse.2013. 84.12 .

28. Kalén A, Rey E, de Rellán-Guerra AS, Lago-Peñas C. Are soccer players older now than before? Aging trends and market value in the last three decades of the UEFA Champions League. Front Psychol. 2019;10:76; doi: 10.3389/ fpsyg.2019.00076.

29. Slimani M, Nikolaidis PT. Anthropometric and physiological characteristics of male soccer players according to their competitive level, playing position and age group: a systematic review. J Sports Med Phys Fitness. 2019;59(1):141-163; doi: 10.23736/S0022-4707.17.07 950-6. 
30. Modric T, Versic S, Sekulic D. Aerobic fitness and game performance indicators in professional football players; playing position specifics and associations. Heliyon. 2020;6(11):e05427; doi: 10.1016/j.heliyon.2020.e05427.

31. Bangsbo J, Mohr M, Krustrup P. Physical and metabolic demands of training and match-play in the elite football player. J Sports Sci. 2006;24(7):665-674; doi: 10.1080/02640410500482529. 